\title{
Mama Spider
}

\author{
Monica Pineda
}

Monica Pineda is a graduate student completing her master's degree in early childhood education at the University of Texas at Austin. She is Salvadoran American and has been an early childhood educator for eight years. In those eight years she has worked with Latino children identified as English language learners in pre-kindergarten and kindergarten classrooms. Email: m.pineda@ utexas.edu

In this paper I share how I, an early childhood educator, respond to the challenge of the Anthropocene. There is a greater need for pedagogies of relationality and a focus on webbing ethical and ecological responsibility with practice. Through a series of pedagogical narrations I restory the coconstruction of the place and space that spiders, young children, and I shared.

Key words: Anthropocene; common worlds; witnessing; early education

\section{Common Worlds}

Affrica Taylor and Veronica Pacini-Ketchabaw (2015) define a common world pedagogy as one that focuses on the collective manners and means through which children learn from engaging with other species, entities and forces in their immediate common worlds" (p. 508). Taylor and her colleague Miriam Giugni (2012) suggest that we must allow young children to learn how to "world." Worlding entails many things, such as

how to be responsible in and for our common worlds; how to bring others into our common worlds; how to form "questioning relationships" with these others; how to negotiate interests in common worlds; and how to practice a relational ethics. (Taylor \& Giugni, 2012, p. 117)

This approach is not to be confused with an idyllic, happy, peaceful ending, but rather is a space where we humans and more-than-human others can "flourish together in difference" (Taylor \& Giugni, 2012, p. 109). Taylor (2011) suggests that it is important to look past the romanticized view of childhood and nature generated by Rousseau's ideas: "Rousseau produced a romantic conflation of nature/childhood/primitivism that immediately evoked an originary higher order state of purity and innocence" (p.423). Accepting Rousseau's dualistic view is to place value on nature and to see culture in opposition to nature. This problematic and limiting view has influenced the way we understand childhood. There is more to be discovered by looking past nature/culture dualisms. Taylor and Giugni (2012) support a "critical place pedagogy that does not shy away from the power relations and struggles that manifest in place" (p. 115). It is a challenge to decenter the child in the classroom, because for educators it is almost an automatic response to focus on what the child is doing and learning. Common worlds pedagogies suggest that educators also focus on the human and more-than-human collective. In doing so, we become aware and responsible for the common interests of human and nonhuman others that are part of communities. To be able to do this work, educators have to think differently about their practice. It suggests a movement away from traditional ways of evaluating and observing young children. The early childhood space is complex and requires that educators be attentive to events that may not seem important. Iris Berger (2015) suggests that a purposeful response and attention to unexpected events can create new understandings about teaching and how young children learn. This knowledge can "orient the ECE community toward thinking that moves beyond generalizations and clichés, because being attentive to unexpected events necessitates creative thought and unprecedented pedagogical responses" (Berger, 2015, p. 131). 
In this study, I respond to a common worlds pedagogy by thinking differently about the relationships between spiders and the children in my kindergarten class. My intention was to be more attuned to more-than human presences and respond to a web of encounters with spiders and place. With common worlds in mind, I began to situate myself in relation to nature and not in opposition to it. Instead of "protecting" young children from spiders or learning about the dangers and reasons to stay away from or "be careful" of spiders, I wanted the children and myself to relate to spiders. This meant we were responsible for learning more than "fun facts" about spiders-a typical kindergarten approach. Responding to a common worlds pedagogy required that the children and I learn with spiders. Through the practice of common worlding, the students and I experienced a journey into the unknown. We learned to build relationships with nonhuman life and the spaces we think we know. What follows is a series of pedagogical narrations I use to document how the children and I built and nurtured new ideas and relationships.

Berger (2015) describes pedagogical narration as a "process through which early childhood educators document and share narratives about significant pedagogical occurrences" in their own classrooms (p. 131). The objective is to generate "critical dialogue where assumptions about early childhood pedagogical practices and children's identities are made visible and open for disputation and renewal” (p. 131). Pedagogical narrations allow us to think differently about young children and early childhood practices. These narrations have the potential to disrupt traditional ways of thinking with and relating to living and nonliving others. Pedagogical narration is one way of documenting relationships with our common worlds and our witnessing of young children and nature. There is no prescriptive formula for educators to follow in documenting or enacting a common worlds pedagogy. This is important to note because this idea was not clear to me until the final stages of the inquiry and as I reflected and wrote about my experience. Blaise, Hamm, and Iorio (2016) point out that pedagogical narrations "are another way to make children's learning visible and like pedagogical documentation can be done through anecdotal observations, collecting children's work, audio and video recordings, photos, and ideas documented by children or teachers" (p. 8). My students and I used pedagogical narration to make visible the relationships and connections among spiders, children, and educator.

It became visible to me that my role as the classroom teacher was one of authority and control. I was in charge of "controlling" the children and their knowledge. Through our inquiry with spiders, I was able to transform my role as educator to one of coconstructor of knowledge, countering my role of knowledge holder. As coconstructors of knowledge, children were encouraged to lead, teach, build, and relate with one another and their surroundings in ways we had not done before. While it was challenging to alter my role and to find myself in situations I had not planned, I also found it liberating that this project allowed me to embrace the idea that "the teacher does not have the answers. Instead, she exposes what she does not know and how she is thinking" (Blaise et al., 2016, p. 8).

I began reflecting on my current practice. I observed the children and listened to their conversations during science instruction. I started to write in a journal. In the journal, I wrote things that I said to the children during the instructional day. When I read my reflections, I thought about who or what was silenced through my words and everyday interactions. It became obvious that the human was at the centre of everything I did and said. I slowly began to see areas of my practice that demanded questioning. My reflections allowed me to shift my practice to one that sought to relate to nonhuman others, and I attempted to decenter myself and the children. I brought these reflections and wonderings to the children, and together we began to think with spiders.

I documented this process through the use of pedagogical narrations. I used pictures, student work samples, audio recordings, and journal writing. I arranged my documentation in chronological order to restory experience. It is not my intent to speak for spiders, young children, or the place and space we shared. My intention is to bring 
others into the relationships that were coconstructed in hopes that they may feel inspired to think with this work. What follows are three pedagogical narrations of our experiences.

\section{Spider Hunt}

After Daddy Long Legs has been gone for several days the children begin to wonder and think about spiders more than before. They are interested in knowing where they live. They want to see them and "catch" them. We go on a spider hunt.

Reflecting on the spider hunt, I realized how humancentric and colonial this activity was. The children and I (the colonizers) were looking to trap and catch spiders in order to put them in small containers for observation. I was frustrated that I did not initially realize the implications of this practice. However, I came to see this activity as an opportunity to engage with common worlding. I became motivated to grapple with the tensions of trying to uphold a common worlds perspective.

My natural impulse was to center the children and myself and demand that spiders serve our curiosity. I countered this impulse by centering the spiders, and I challenged myself to think about how to relate to spiders. I wanted to listen, connect, and respond to spiders, not command them to do as we said. In Bruno Latour's words:

The insistence that we live in not just exclusively human societies but in common worlds with other species runs counter to the human-centric impulse to divide ourselves off from the rest of the world and re-enact the self-perpetuating nature/culture divide. (2004, as cited in Pacini-Ketchabaw, Taylor, \& Blaise, 2016, p. 150)

I pivot our attention by imagining what thinking with spiders might look like in practice. I decide that we must elevate the existence and the life of a spider. I acknowledge that I do not know much about spiders, nor have I respected and honoured our interconnectedness before. Working with the children to disrupt human-centered practices, we play games and pretend to embody spiders. We walk, move, and talk in ways we imagine a spider would. As we move away from human-centeredness and explore common worlding with spiders, I generate questions to pose to the children. My goal is to provoke them to think with spiders. For example: If you were a spider where would you live? What would be the ideal home for a spider? What would a spider house look like? I document the students' answers on chart paper (see Figure 1). During our discussion, the children generate many ideas about what might be important in a spider's home. Some of the children decide to put their ideas in writing.

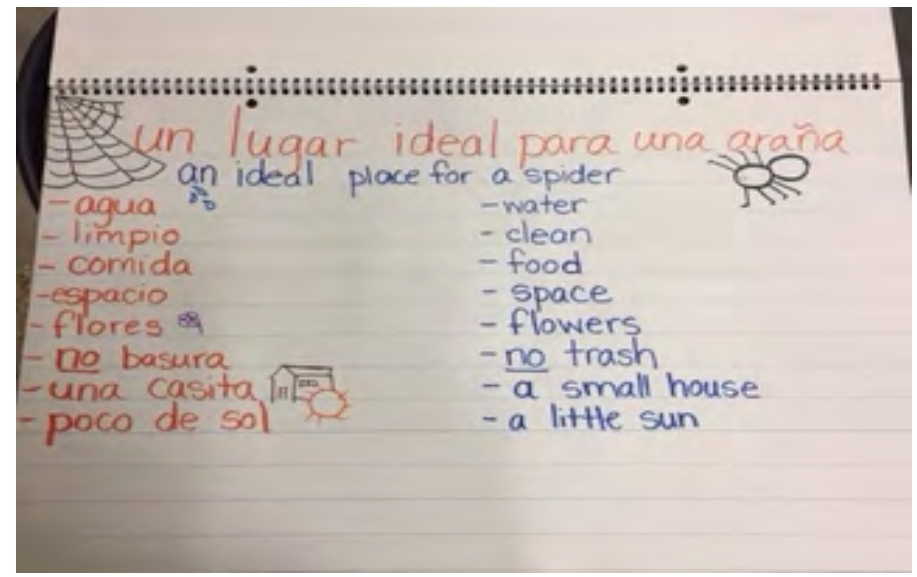

Figure 1. This chart shows the children's answers and thoughts as we attempted to think with spiders.
This activity provokes a shift from a desire to trap or catch spiders toward a sense of care. The children wonder if they can make the spaces around them more spider friendly. They collectively decide that the best place for a spider to live might be the "little park." The little park is the school playground we visit every day for recess. It is between the school building and the teacher parking lot. It is enclosed by a fence and a stone wall. In the centre of the park is a yellow playscape. Between the stone wall and the playscape are empty garden beds that are unattended (see Figures 2 and 3 ). The beds are filled with soil, overgrown shrubs, and trash. The children decide it would be a good idea to clean out one of the garden beds 


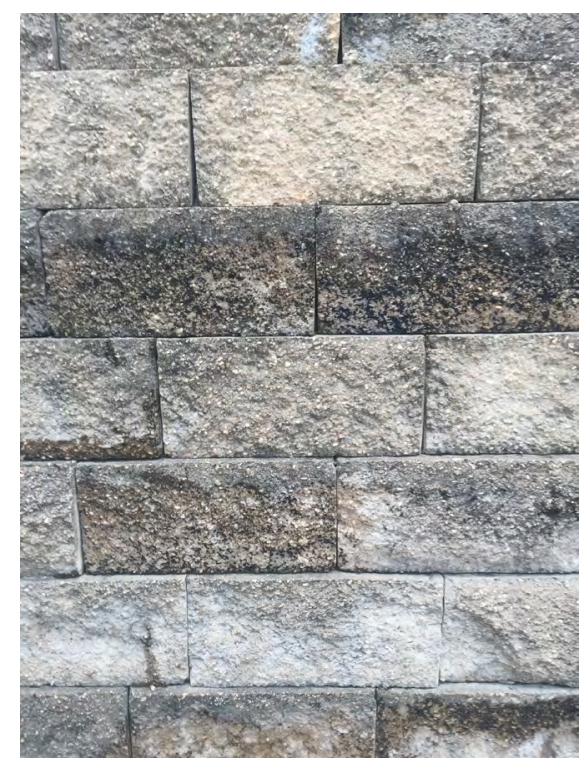

Figure 2: This stone wall surrounds one side of the little park.

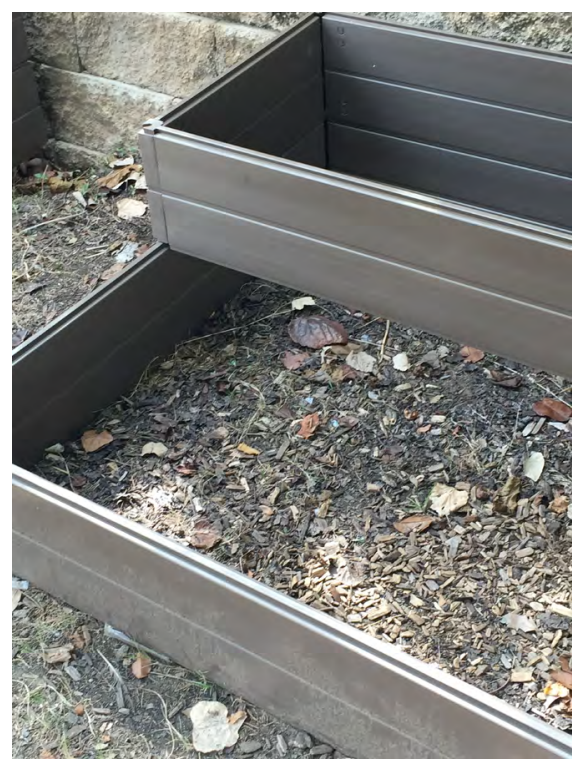

Figure 3: Empty garden beds located in the little park that seem to be unattended.

and create a welcoming space for spiders. The children and I build a spider garden. I decide to offer my help and they give me instructions. At times they request that I cut or remove overgrown grass and they dig their hands into the soil. They find worms and small insects. Some children want to get a close look at the worms while others touch them, pick them up, and pass them around in damaging ways. I realize in that moment that I do not want them to do that, because they are not being careful. I feel uncomfortable, because I can see our curiosity has resulted in dead insects and worms. I had not anticipated this result, and I feel that this activity has failed. I try to interfere, without really knowing how or what to say. I remind the children that we are hoping to make this a welcoming

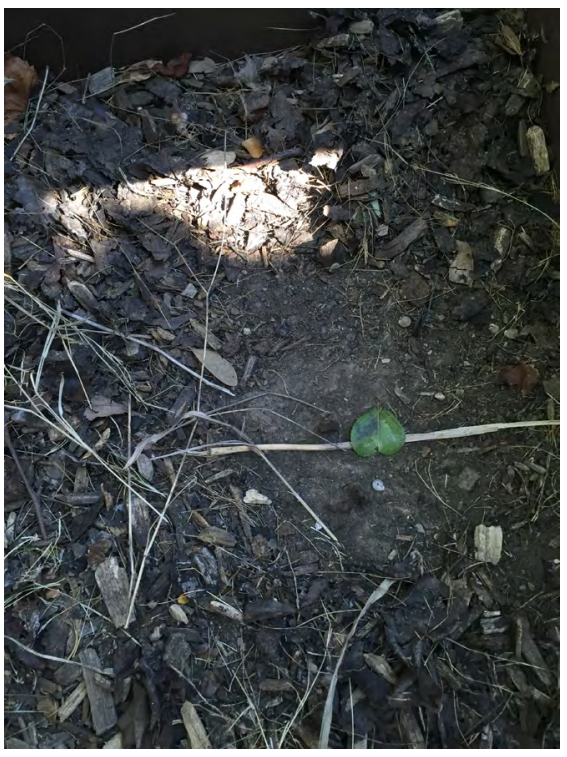

Figure 4. Heart-shaped leaf placed by children to serve as a pillow for spiders. space for spiders, that life exists here, and we should be careful not to destroy it. It is a difficult tension. I can see that we are building relations with spiders, yet we are still insensitive to other more-than-human life. Before we go inside for the day, the children place a heart-shaped leaf in the garden bed, saying that it will be a "pillow for spiders to rest" (see Figure 4).

The following day when we visit the little park, the children remember creating a space for spiders to inhabit the empty garden bed. They run with excitement toward the garden bed. They are disappointed when they do not see spiders. The children wonder where the heart pillow went and why the spiders did not visit the home they built. The children head home for the day, and I reflect on that day's events.

I was excited that the children had moved away from wanting to trap spiders. I now realize that manipulating the land and directing them to a certain place for our viewing and learning pleasure may not be such a good idea. Am I teaching them subtle ways of colonizing nature and not holding ourselves accountable for our actions? How is this spider garden any different if we are killing and disrupting the life that exists there to attract spiders? 


\section{Noticing and Listening}

I challenge myself and the children to listen and connect to a place we think we know. We visit the playground daily. We have stepped into every possible space encompassed by the stone wall, the school building, and the fence. I want us to witness and notice with spiders. This requires attending to the more than-human, which involves understanding that "we are entangled with all sorts of forces, elements, and species beyond" ourselves (Blaise et al., 2016, p. 9). I invite the children to reconnect with their spider senses and thus notice with attentiveness. The students notice many things in the very space they have played in and explored for three months. There is evidence in their conversations that our lives overlap with other nonhuman life. As Thom van Dooren, Eben Kirksey, and Ursula Münster (2016) write, "paying attention can and should be the basis for crafting better possibilities for shared life" (p. 17).

The children seem to be confusing spider webs with spiders, but nonetheless they are aware of other life. Every time they see a spider web they scream for my attention and carefully walk me over to all the things they are noticing. They warn me to be gentle with my feet because spiders could be walking underneath my feet. They are aware that spiders walk on the same ground we step and run on as we play in the little park. They urge me to take pictures of the spiders and wonder if they are afraid of us since we must look like "giants" to them (see Figures 5 and 6).

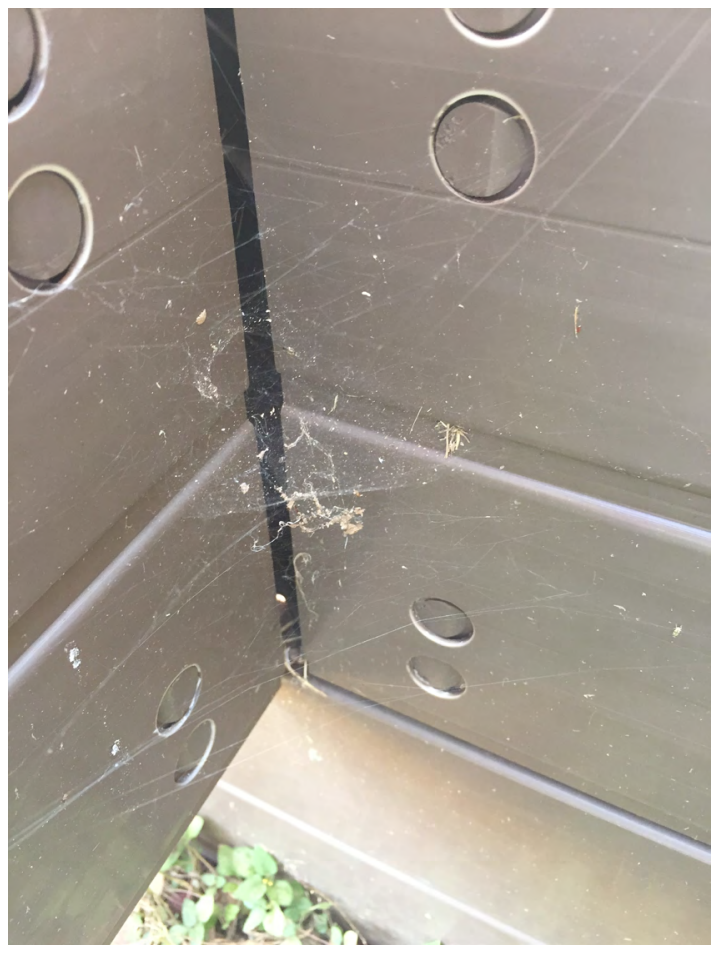

Figure 5. The children find spider webs and refer to them as spiders and request I take pictures of them.

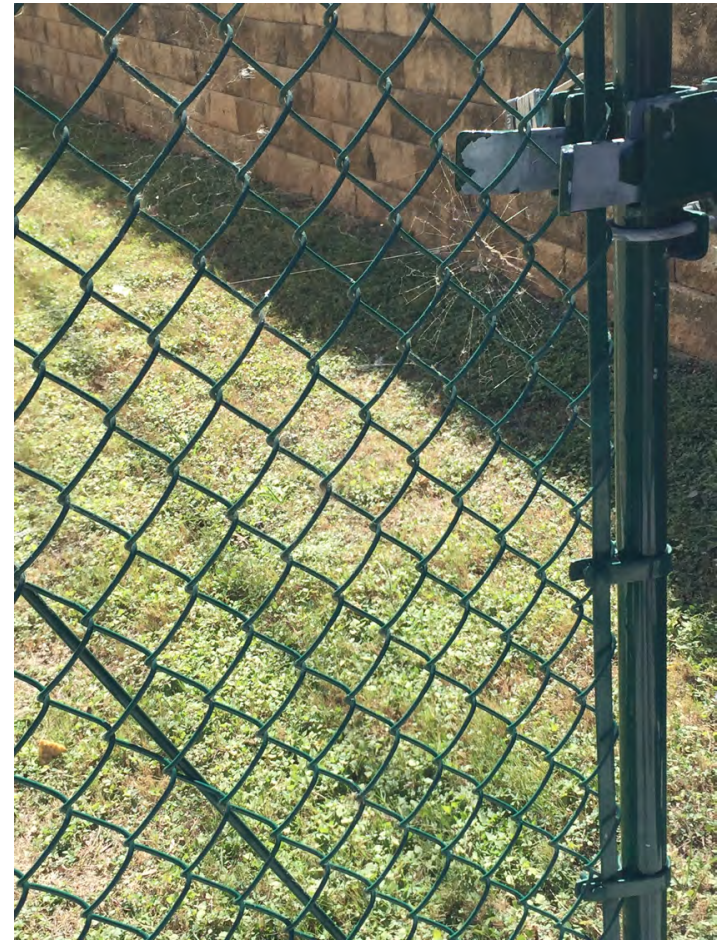

Figure 6. The children find more spider webs around the park.

The children begin to pay attention to their surroundings and seem to have a heightened awareness. They are thinking with spiders. They notice spiders and spider webs in their homes, in books, in movies, in cartoons, in songs, and on their clothes and shoes. They want to learn how to draw spiders and spider webs. Some children persuade their parents to buy them toy spiders to bring to class for show-and-tell. Since the visit from Daddy Long Legs, they have not had any encounters with real spiders in school. 


\section{Mama Spider}

After several weeks of careful noticing, the children encounter a real spider! The children are very excited about their encounter, and some journal about it. After finding the spider, day after day the children check the spot and find that the spider is still there. We notice a round white object that seems to be stuck on the spider web. The children are sure it was not there yesterday. We decide that we think it looks like an egg sac. The children are so excited about their encounter with the spider and the egg sac that they share the news with friends from other classrooms. Walking back into the building, I hear the children wonder how long it will take for the babies to come out of the egg. They seem more curious and thoughtful. The children begin thinking of names for the babies and they are eager to see what will happen tomorrow (see Figure 7).

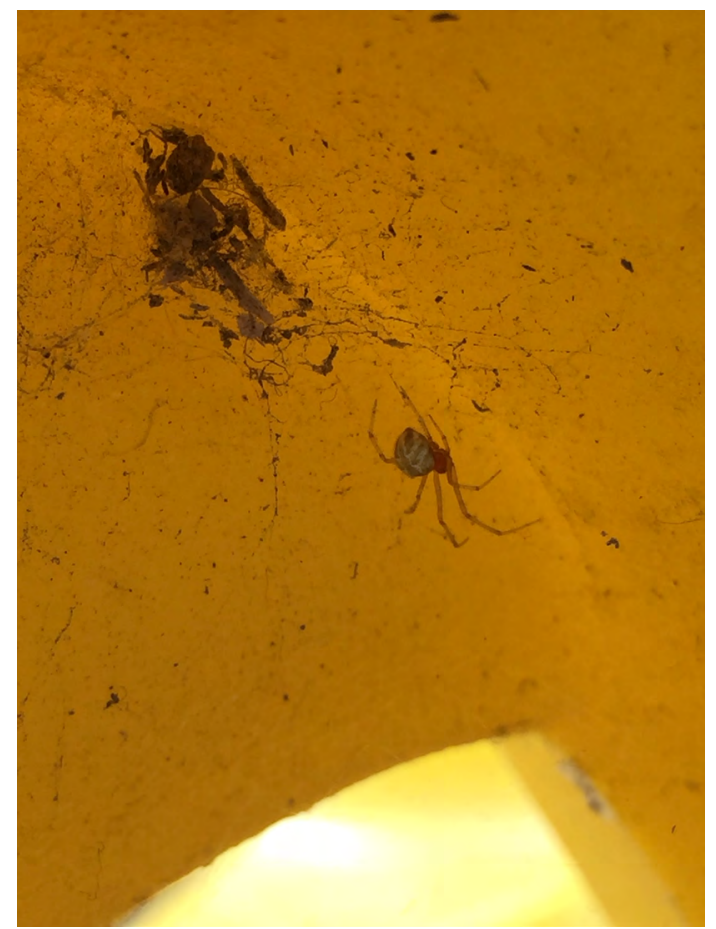

Figure 7. The children find a spider and name her "Mama Spider."

The children quickly learn about the loss of life when one curious friend picks the egg sac out of the web to show it to someone else. This destroys the egg sac and troubles the children. When they ran over to tell me what had happened, I was upset. I felt their expectation was that I would "fix" the situation. In the moment I froze, their voices were full of urgency and concern, but I did not say a word. I did not know what to say or do. I knew the egg sac was gone and there was nothing I could do about it, but I could not bring myself to say that to the children. I thanked them for informing me of what had happened. I told them we would talk about what had happened when we were back in the classroom, and I encouraged them to go back to their play.

Once we were back in the classroom, we started talking about Mama Spider and what had happened to the egg sac. They expressed feeling confused, "mad," and "sad." Many could not understand why it was necessary to remove the egg sac to observe it. They worried about Mama Spider and her babies. They worried about friends who destroy the things they love and care about. Through whole-group discussion, we talked about how Mama Spider and the babies may have felt. The children extended well-wishes to the spider and also to the friend who removed the egg sac. The children decided it was important to teach friends to not hurt spiders and spider babies. Children wrote letters of encouragement to each other and to the friend who destroyed the egg sac. Some children chose to write to Mama Spider. They thanked Mama Spider for stopping by and said they hoped that "one day she can come back."

Although Mama Spider is not visible anymore, the children are still thinking about her and other spiders. The children create a "spider community" of wooden sticks, which they think makes a good home for spiders. They tell me the sticks are hard and will protect the spiders, who will be able to hide under the sticks if they need to. The children play, walk, jump, and run around the spider community. They are careful and warn their friends when they get too close. As they play and become interested in other aspects of their surroundings, they continue to be aware of the spider community and express their desire to protect it. 


\section{Conclusion}

This project aimed to disrupt Rousseau's romanticized nature-child pedagogies that view "nature as the child's best teacher" (Taylor \& Giugni, 2012, p. 114). I wanted to employ a common worlds pedagogy and steer away from perpetuating colonial ways of thinking and being with nature and place. Latour's notion of common worlds (as cited by Blaise et al., 2017) is a way to not separate children and adults from nature. Blaise et al. (2017) explain that it "takes an inclusive understanding of the world where past, present, and future lives are entangled" (p. 2). The children and I began by attempting to build a spider garden as a meaningful response to the children's interest in spiders after the visit from Daddy Long Legs. I researched which plants and what conditions were best to attract spiders. The children and I thought about the available outdoor space, and we decided that the empty garden beds along the edge of the playground where the children played every day was an accessible area. I was, however, troubled by the humancentric approach of manipulating the land and the spiders. I was troubled by not having a clear answer or method to approach the project. I was committed to noticing and remaining open to what the project might become through a willingness to "refigure and complicate what is considered present in everyday child-educator community garden encounters" (Nxumalo, 2016, p. 131). My hope was to disrupt my practice and my own ideas of environmental education in the early childhood classroom. Instead of viewing my practice and our encounters with spiders and nature in isolation and without implications, I understood that I make pedagogical decisions that are intentional, political, and filled with tensions.

I made a conscious effort to be more reflective and to accept that I did not have control nor answers. I made efforts to decenter humancentric practices through common worlding. As Taylor and Giugni (2016) suggest, place is an important concept in understating common worlds because it is the "locus of human and more than human differences and relations" (p. 108). I began to shift the way I see the place we play in every day, and I wanted to convey that to the children. I was more thoughtful about what questions I asked and which stories we were paying attention to. I was uncomfortable with this, because I was worried about silencing important voices. I did not want to speak for the spiders, soil, spider webs, insects, grass, trees, children, or the place we called the little park.

The destruction of Mama Spider's egg sac was troubling for me. I understood that I had to be honest with myself and the children. I knew there would come a time when the project would end and I would not have the answers children sought. I knew I would not be prepared because I did not know how learning events would unfold. I also knew we were going to have to face a difficult situation at some point, and I was committed to grappling with the implications of our actions. However, when Mama Spider's egg sac was destroyed, I was not ready. I was speechless and offered no comfort to the children. It was uncomfortable, but it was reality. It certainly was not romantic, idyllic, nor a happy ending. Reflecting on the project, I still question whether my reaction was fitting. I know worlding is not an easy alternative. Instead, it requires a "continual grappling" (Taylor \& Giugni, 2012, p. 113) that can mean we simply "stay with the trouble" (Potts \& Haraway, 2010, p. 327) that emerges as we learn with our common worlds.

There are no promises or concrete solutions in practices of worlding. However, within uncomfortable situations that challenge our thinking, there is potential to learn otherwise. Mama Spider continues to guide my practice in ways that are attentive to more-than human worlds. I see the potential of worlding in shaping an attentive environmental education that responds to the unexpected moments of teaching and learning with children and more-than human others. Through continued reflection, I know that Mama Spider will continue to teach me otherwise. 


\section{References}

Berger, I. (2015). Pedagogical narrations and leadership in early childhood education as thinking in moments of not knowing. Canadian Children, 40(1), 130-147. Retrieved from https://journals.uvic.ca/index.php/jcs/article/download/15215/6856

Blaise, M., Hamm, C., \& Iorio, J. M. (2017). Modest witness(ing) and lively stories: Paying attention to matters of concern in early childhood. Pedagogy, Culture, \& Society, 25(1), 31-42. doi: 10.1080/14681366.2016.1208265

Nxumalo, F. (2016). Touching place in childhood studies: Situated encounters with a community garden. In H. Skott-Myhre, V. PaciniKetchabaw, \& K. Skott-Myhre (Eds.), Youth work, early education, and psychology (pp. 131-158). New York, NY: Palgrave Macmillan. doi: 10.1057/9781137480040_8

Pacini-Ketchabaw, V., Taylor, A., \& Blaise, M. (2016). Decentring the human in multispecies ethnographies. In C. A. Taylor \& C. Hughes (Eds.), Posthuman research practicesineducation(pp.149-167).London,UK:Palgrave Macmillan.doi: 10.1057/9781137453082_10

Potts, A., \& Haraway, D. (2010). Kiwi chicken advocate talks with Californian dog companion. Feminism \& Psychology. doi: $10.1177 / 0959353510368118$

Taylor, A. (2011). Reconceptualizing the "nature" of childhood. Childhood, 18(4), 420-433. doi: 10.1177/0907568211404951

Taylor, A., \& Giugni, M. (2012). Common worlds: Reconceptualising inclusion in early childhood communities. Contemporary Issues in Early Childhood, 13(2), 108-119. doi: 10.2304/ciec.2012.13.2.108

Taylor, A., \& Pacini-Ketchabaw, V. (2015). Learning with children, ants, and worms in the Anthropocene: Towards a common world pedagogy of multispecies vulnerability. Pedagogy, Culture, \& Society, 23(4), 507-529. doi: 10.1080/14681366.2015.1039050

van Dooren, T., Kirksey, E., \& Münster, U. (2016). Multispecies studies: Cultivating arts of attentiveness. Environmental Humanities, 8(1), 1-23. doi: $10.1215 / 22011919-3527695$ 